\title{
A Note on Units of Measurement, Romanization, and Dates
}

All monetary units in this book appear as Chinese dollars (yuan) unless otherwise indicated. In 1997 and 1998 the official renminbi-U.S. dollar exchange rate was about 8. Io yuan = I U.S. dollar. One Chinese mile $(l i)$ $=1 / 2$ kilometer (distances in this book are described either in kilometers or $l i$, depending on the context); one Chinese $j i n=1 / 2$ kilogram.

The pinyin system of romanization of Mandarin Chinese is used for most Chinese expressions, e.g. (miaohui). Specifically Shaanbei dialect expressions are transliterated into pinyin and are indicated with an "S," e.g. (S. shouku). When the Shaanbei expression is the same as that in Mandarin but with only slight difference in pronunciation, I romanize the expression in standard Mandarin.

Most dates in this book are in the lunar calendar count, following the customary usage of most Shaanbei people, especially when the dates of temple festivals are concerned. Instead of writing "the third of the third month" or "the thirteenth of the sixth month" I have chosen to represent the dates as "Third Month Third" and "Sixth Month Thirteenth" to try to capture the flavor of the Chinese original, i.e., sanyue san and liuyue shisan. Dates that stand for special occasions such as temple festivals and traditional calendrical festivals are capitalized. 



\section{Miraculous Response}

Doing Popular Religion in

Contemporary China 
